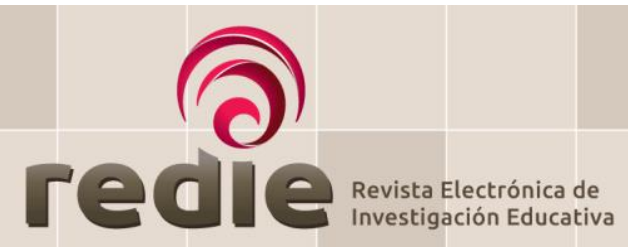

ISSN: $1607-4041$

https://redie.uabc.mx

Vol. 23, 2021/e1r

\title{
Educación Superior Intercultural: desafíos desde los entornos locales
}

Martín de la Cruz López Moya (*) https://orcid.org/0000-0002-9119-0713

(*) Universidad de Ciencias y Artes de Chiapas

Cómo citar: López, M. de la C. (2021). Educación superior intercultural: desafíos desde los entornos locales. Revista Electrónica de Investigación Educativa, 23, e1r, 1-3. https://doi.org/10.24320/redie.2021.23.e1r.4726

Bermúdez, F. M. (2020). Agencia social y educación superior intercultural en Jaltepec de Candayoc, Mixe, Oaxaca. Universidad de Ciencias y Artes de Chiapa / Instituto Superior Intercultural Ayuuk, 253 pp.

El aporte de este libro reside en el énfasis sobre los procesos creativos y de agenciamiento social en los entornos locales que la autora elige como eje de argumentación. Destaca el valor que adquiere sistematizar y comprender las prácticas adoptadas entre los agentes sociales para hacerse sujetos activos de su devenir como colectivo y como proyecto educativo. Desde mi experiencia como sociólogo y antropólogo, considero pertinente destacar la relevancia social y académica que adquiere esta obra. He tenido la oportunidad de conocer diversos proyectos de corte político y social en distintos momentos y espacios en el sur de México y he podido constatar que, en la mayoría de los casos, se sustentan en narrativas victimizantes al colocar a los sujetos (que idealmente tratan de defender) como sujetos pasivos e incapaces de proponer alternativas de desarrollo en sus entornos inmediatos. Estos discursos que abrevan en lugares comunes resultan más bien contraproducentes cuando se trata de apoyar proyectos alternativos de desarrollo humano.

En la presente reseña comento algunos temas que me deja la lectura del libro de Bermúdez, que tienen que ver con aspectos de forma y también sobre sus contenidos. Primero, es necesario situar la relevancia de la experiencia de la educación intercultural que se propuso estudiar la autora, y destacar el valor que adquiere la publicación de un libro de esta naturaleza para la Universidad de Ciencias y Artes de Chiapas y para la investigación que se realiza desde el sur del país desde las Ciencias Sociales y las Humanidades, más allá de las fronteras con Chiapas, en este caso, en la región Mixe de Oaxaca.

Agencia social y educación superior intercultural en Jaltepec de Candayoc... es un proyecto bien cuidado en su estructura y producción editorial. Cuenta con cinco capítulos, presentación y conclusiones. Primero, la autora coloca su estudio dentro del campo de reflexión sobre la educación intercultural como una práctica de agenciamiento social y propone un andamiaje teórico que da coherencia y sentido a los enfoques adoptados, lo que permite tener una idea de interculturalidad en los procesos educativos como resultado de la convergencia de actores sociales y de saberes múltiples.

Los capítulos dos y tres son de orden etnohistórico: muestran el devenir de la escolarización en Oaxaca, desde el papel que jugó la Iglesia durante la colonia, pasando por el nacimiento de la escuela pública, hasta las dinámicas sobre la autonomía educativa emprendida por maestros a finales del siglo pasado.

Examina, después, discursos y resistencias por el cuidado y sentido de pertenencia a la región mixe y la comunalidad entre los ayuuk, lo que se traduce en narrativas sobre un pasado mítico que sirve como recurso de reivindicación identitaria y de posicionamiento político. Más adelante, se centra en las dinámicas de escolarización en el distrito mixe, para luego profundizar en la creación del Instituto 
Superior Intercultural Ayuuk (ISIA), donde la convergencia de saberes y actores sociales diversos hacen del ISIA un proyecto educativo exitoso, con una clara apuesta hacia la traducción intercultural.

Bermúdez elige una perspectiva de carácter procesual y relacional, si bien los sujetos de su estudio se adscriben y se asumen como pertenecientes a etnias de Oaxaca. Lo que más destaca del volumen es que la autora asume una distancia reflexiva sobre aquellos enfoques que han pretendido ver a los pueblos indígenas como sociedades homogéneas y estáticas; toma también distancia de perspectivas folclorizantes y paternalistas que tanto han caracterizado las investigaciones realizadas sobre la población hablante de lenguas indígenas.

En su conjunto, el libro analiza una experiencia de educación superior intercultural que se está produciendo en un pueblo mixe de Oaxaca: la creación del Instituto Superior Intercultural Ayuuk, un proyecto de educación alternativo que si bien es exitoso -como lo muestra la autora- está aún en proceso. Desde el inicio, el libro traza una perspectiva que privilegia la categoría de agencia social, una categoría ampliamente utilizada para describir o interpretar procesos sociales asociados a la movilización o la resistencia, pero que es exitosamente aplicado a los procesos educativos.

En su estancia en la localidad de Jaltepec de Candayoc Mixe, Bermúdez logra recuperar cómo se gestan y recuperan momentos históricos que dan sentido a la creación del instituto, que lo colocan como un proyecto paradigmático para el diálogo intercultural entre actores sociales diversos, individuales, colectivos e institucionales.

En el libro es posible ver varios niveles de aproximación que van desde la antropología y sociología de la educación, la antropología política, la pedagogía de corte intercultural, la perspectiva histórica, el método etnográfico, el registro de información empírica, observaciones y diálogos con diversos actores.

Un eje transversal del texto es el énfasis en la convergencia y el entramamiento de diversos proyectos, anhelos y utopías entre actores sociales inmersos en los entornos educativos, pero también de residentes y visitantes solidarios con los procesos comunitarios y con aspiraciones para traer la universidad a un espacio rural, que tuviera como proyecto común el desarrollo comunitario. A pesar que se desarrolla en un entorno hostil, no sólo por el abandono, la inseguridad y, a veces, excluido de los planes educativos de los gobiernos de todos los niveles.

Es el encuentro de múltiples actores que dialogan para dar continuidad a un proyecto educativo que adopta la experiencia de educación local que, a su vez, dialoga con procesos educativos más amplios, de apropiaciones de múltiples saberes y que se coloca en armonía con la propuesta de educación que también se inscribe en el marco del Sistema Universitario Jesuita (SUJ). Entre los actores en este proyecto común destacan los pobladores de larga residencia en el lugar y de visitantes, alumnos, maestros locales y visitantes de la Universidad Iberoamericana, agentes religiosos, gestores culturales y personas adscritas a diversos proyectos de solidaridad con las causas indígenas.

Recupera los imaginarios tanto de los proyectos educativos locales y de adscripción cultural y a los territorios, que abrevan las narrativas que dan sentido de pertenencia de un programa educativo como propio, el cual se inspira en la tradición en lo comunal local, en diálogo como procesos educativos públicos y privados mas amplios.

La experiencia de creación y desarrollo del ISIA es ejemplo de un programa de educación en traducción intercultural con logros exitosos, que bien podría replicarse en otros contextos; lo mismo podría tomarse como referente el modelo y estrategia metodológica que la autora adoptó para llevar a cabo su investigación, para realizar otras investigaciones sobre el campo educativo o de cualquier otra investigación en ciencias sociales y humanidades.

Así pues, por su contenidos y condiciones de elaboración, recomiendo ampliamente la lectura el libro Agencia social y educación superior intercultural en Jaltepec de Candayoc Mixe en Oaxaca, un libro que 
puede ser de interés no solamente para los expertos de la educación intercultural sino también para aquellos interesados en la educación comparada y las iniciativas endógenas de corte educativo entre los pueblos indígenas de Oaxaca. 